\title{
Effects of betaine on lipopolysaccharide-induced memory impairment in mice and the involvement of GABA transporter 2
}

\author{
Masaya Miwa', Mizuki Tsuboi ${ }^{2}$, Yumiko Noguchi ${ }^{2}$, Aoi Enokishima², Toshitaka Nabeshima ${ }^{2}$ and \\ Masayuki Hiramatsu ${ }^{1,2^{*}}$
}

\begin{abstract}
Background: Betaine (glycine betaine or trimethylglycine) plays important roles as an osmolyte and a methyl donor in animals. While betaine is reported to suppress expression of proinflammatory molecules and reduce oxidative stress in aged rat kidney, the effects of betaine on the central nervous system are not well known. In this study, we investigated the effects of betaine on lipopolysaccharide (LPS)-induced memory impairment and on mRNA expression levels of proinflammatory molecules, glial markers, and GABA transporter 2 (GAT2), a betaine/ GABA transporter.
\end{abstract}

Methods: Mice were continuously treated with betaine for 13 days starting 1 day before they were injected with LPS, or received subacute or acute administration of betaine shortly before or after LPS injection. Then, their memory function was evaluated using Y-maze and novel object recognition tests 7 and 10-12 days after LPS injection (30 $\mathrm{mg} /$ mouse, i.c.v.), respectively. In addition, mRNA expression levels in hippocampus were measured by real-time RT-PCR at different time points.

Results: Repeated administration of betaine $(0.163 \mathrm{mmol} / \mathrm{kg}$, s.c.) prevented LPS-induced memory impairment. GAT2 mRNA levels were significantly increased in hippocampus $24 \mathrm{hr}$ after LPS injection, and administration of betaine blocked this increase. However, betaine did not affect LPS-induced increases in levels of mRNA related to inflammatory responses. Both subacute administration ( $1 \mathrm{hr}$ before, and 1 and $24 \mathrm{hr}$ after LPS injection) and acute administration (1 hr after LPS injection) of betaine also prevented LPS-induced memory impairment in the Y-maze test.

Conclusions: These data suggest that betaine has protective effects against LPS-induced memory impairment and that prevention of LPS-induced changes in GAT2 mRNA expression is crucial to this ameliorating effect.

\section{Background}

Betaine (glycine betaine or trimethylglycine) is widely distributed in plants and microorganisms as well as in various dietary sources $[1,2]$. Some plants accumulate high levels of betaine in response to abiotic stress, and both exogenous application of betaine and the introduction via transgenes of the betaine-biosynthetic pathway into plants that do not naturally accumulate betaine increase the tolerance of these plants to various types of

\footnotetext{
* Correspondence: mhiramt@meijo-u.ac.jp

'Laboratory of Neuropsychopharmacology, Graduate School of Environmental and Human Sciences, Meijo University, 150 Yagotoyama, Tenpaku-ku, Nagoya 468-8503, Japan

Full list of author information is available at the end of the article
}

abiotic stress, such as drought, high salinity, and temperature stress [3].

In humans, betaine is obtained from the diet [2] or from its metabolic precursor choline [4]. Betaine is utilized as a methyl donor in a reaction that converts homocysteine into methionine via betaine-homocysteine methyltransferase. Betaine also plays a role in osmotic regulation in the kidneys, which are routinely exposed to high extracellular osmolarity during normal operation of the urinary concentrating mechanism [5]. Furthermore, dietary betaine suppresses the activation of nuclear factor $-\kappa \mathrm{B}(\mathrm{NF}-\kappa \mathrm{B})$ with oxidative stress, and the protein expression of proinflammatory molecules such as cyclooxygenase-2 (COX-2), inducible nitric oxide

\section{C) Biomed Central}


synthase (iNOS), and tumor necrosis factor (TNF)- $\alpha$ in aged rat kidneys [6,7].

Betaine/GABA transporter-1 (BGT-1), the mouse transporter homologue of which is known as GABA transporter 2 (GAT2), is an integral membrane transporter capable of utilizing both betaine and GABA as substrates $[8,9]$. The distribution pattern of GAT2 mRNA does not closely match that of GABAergic pathways [8]. In a culture study, Olsen et al. [10] suggested that astroglial GAT2 expression and function are regulated by hyperosmolarity. Zhu \& Ong [11] reported that BGT-1 expression is upregulated after kainite-induced neuronal injury in rat hippocampus. These reports suggested that GAT2/BGT-1 plays a role in osmoregulation in neural cells and that upregulation of GAT2/BGT-1 expression contributes to astrocytic swelling after brain injury. Interestingly, since GAT2 is co-localized with Pglycoprotein, a blood-brain barrier (BBB)-specific marker, in brain capillaries [12], it may also be involved in betaine transport across the BBB. These data suggest that betaine attenuates inflammatory processes and/or oxidative stress; however, the effects of betaine on central nervous system function in animals are poorly understood.

Lipopolysaccharide (LPS), a component of the cell wall of Gram-negative bacteria, is used to experimentally induce memory impairment, neuroinflammatory responses, and oxidative stress such as increases in mRNA levels of interleukin (IL)-1ß and IL-6 [13], heme oxygenase-1, microglial activation [14], and iNOS activity in hippocampus [15]. As neuroinflammation and oxidative stress are critical components of the pathogeneses of some neurodegenerative disorders, including Alzheimer's disease [16-18], and induce learning and memory impairment in rats [14], it is important to elucidate whether betaine improves LPS-induced memory impairment in order to understand the mechanism of action of betaine in the central nervous system.

In this study, we investigated the effects of betaine on LPS-induced memory impairment using the Y-maze and novel object recognition tests. We also examined the effect of betaine on LPS-induced changes in mRNA expression levels of proinflammatory molecules, glial markers, and GAT2 using real-time RT-PCR.

\section{Methods \\ Animals}

Male ddY strain mice (7-9 weeks old, 26 g - 44 g; Japan SLC., Hamamatsu, Japan) were used. The mice were kept in a regulated environment $\left(24 \pm 1^{\circ} \mathrm{C}, 55 \pm\right.$ $5 \%$ humidity) under a 12-h light/dark cycle (lights on 7:45 a.m.) and given food and tap water ad libitum. The experimental protocols concerning the use of laboratory animals were approved by the animal ethics board of Meijo University and followed the guidelines of the Japanese Pharmacological Society (Folia Pharmacol. Japon, 1992, 99: 35A); the Interministerial Decree of May 25th, 1987 (Ministry of Education, Japan); and the National Institutes of Health Guide for the Care and Use of Laboratory Animals (NIH Publications No. 8023, revised 1978). All efforts were made to minimize animal suffering and to reduce the number of animals used.

\section{Drugs}

Betaine hydrochloride (betaine; Sigma, St. Louis, MO, USA) was dissolved in $0.9 \%$ saline and injected subcutaneously (s.c.). Lipopolysaccharide from Escherichia coli 0111:B4 (LPS; Sigma) was dissolved in 0.9\% saline and administered intracerebroventricularly (i.c.v.) into the lateral ventricle of the mouse brain according to the method of Haley \& McCormick [19] at a dose of $5 \mu \mathrm{L} /$ mouse under brief ether anesthesia. I.c.v. injections of LPS or saline were delivered at a rate of $5 \mu \mathrm{L} / 15 \mathrm{sec}$ and injection needles were left in place an additional 10 sec. The total injection volume into the lateral ventricle was based on previous reports [13] and we confirmed that there are no influences of i.c.v. injection of saline (5 $\mu \mathrm{L}$ ) itself on mouse behavior. The sham control animals were administered the vehicle (i.c.v. and s.c.) instead of one of the drug solutions.

\section{Experimental schedules}

First, we investigated whether betaine alleviated LPSinduced memory impairment using the Y-maze and novel object recognition tests, which were carried out 7 and 10-12 days after the LPS injection $(30 \mu \mathrm{g} /$ mouse, i.c.v.), respectively. Time schedules of behavioral experiments were referred to a previous report [15], which showed that LPS-induced memory impairment persists at least 15 days after LPS injection. To investigate the effects of repeated administration of betaine, mice were continuously treated with betaine (0.081, 0.163 , or $0.326 \mathrm{mmol} / \mathrm{kg}$, s.c.) for 13 days starting 1 day before LPS injection. On the day of the tests, betaine was administered $30 \mathrm{~min}$ before the start of the tests (Figure 1A). Proinflammatory molecules and glial activation are important for the pathogenesis of LPS-induced memory impairment, so we measured LPS-induced changes in mRNA expression of proinflammatory molecules and glial markers. The expression of each mRNA was measured $6 \mathrm{hr}$ (proinflammatory molecules) or $24 \mathrm{hr}$ (glial markers and betaine transporter) after LPS injection (Figure 1A). To investigate the effects of subacute administration of betaine, mice were treated with betaine $(0.163$ $\mathrm{mmol} / \mathrm{kg}$, s.c.) $1 \mathrm{hr}$ before, 1 and $24 \mathrm{hr}$ after LPS injection (Figure 1B). 


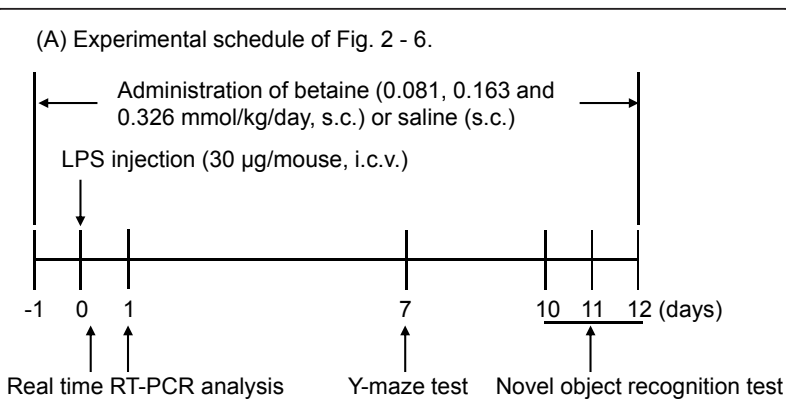

(B) Experimental schedule of Fig. 7.

LPS injection (30 $\mu \mathrm{g} /$ mouse, i.c.v.)

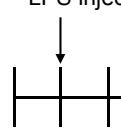

$\begin{array}{lll}-1 & 0 & 1\end{array}$

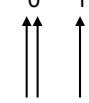

Administration of betaine $(0.163 \mathrm{mmol} / \mathrm{kg}$, s.c.)

or saline (s.c.) $1 \mathrm{hr}$ before, 1 and $24 \mathrm{hr}$ after LPS injection

(C) Experimental schedule of Fig. 8.

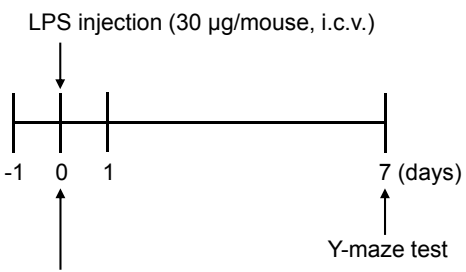

Administration of betaine $(0.163 \mathrm{mmol} / \mathrm{kg}$, s.c. $)$ or saline (s.c.) $1 \mathrm{hr}$ before or after LPS injection

Figure 1 Experimental schedules.

\section{Spontaneous alternation performance (Y-maze test)}

Immediate working memory was assessed by recording spontaneous alternation behavior during a single session in a Y-maze [20] made of black painted wood. Each arm was $40 \mathrm{~cm}$ long, $12 \mathrm{~cm}$ high, $3 \mathrm{~cm}$ wide at the bottom, $10 \mathrm{~cm}$ wide at the top, and converged in an equilateral triangular central area. The procedure was similar to that described previously [21]: each mouse, none of which had any prior experience with the maze, was placed at the end of one arm and allowed to move freely through the maze during an 8-min session, and arm entries were counted. Each series of arm entries was recorded visually, and an arm entry was defined as when the hind paws of the mouse were completely within the arm. Alternation was defined as successive entries into the three arms in overlapping triplet sets. The percentage alternation was calculated using the following formula:

$$
\frac{\text { number of alternations }}{\text { total number of arm entries }-2} \times 100 \%
$$

\section{Novel object recognition test}

The novel object recognition test, which was described previously [22], was used with some modifications. The apparatus consisted of a wooden open-field box $(30 \times 30 \times 35 \mathrm{~cm}$ high $)$. The task was divided into three different sessions (the habituation, familiarization, and retention sessions) and carried out for three consecutive days. On the first and second days, the mice were habituated to the experimental conditions and open-field apparatus without objects for $15 \mathrm{~min} /$ day. On the third day, the mice participated in a 5 -min familiarization session in the presence of two identical objects (cylindrical columns). The time spent exploring each object, which was defined as when a mouse orientated their head toward the object and approached it (within $1 \mathrm{~cm}$ ), was assessed manually using a stopwatch. Immediately after the familiarization session, the mice were removed from the apparatus, and one of the familiar objects was randomly replaced with a novel object (triangle pole). The mice were then returned to the apparatus and participated in a 5 -min retention session in the presence of the familiar object and the novel object. The time spent exploring the familiar and novel objects was manually measured for $5 \mathrm{~min}$. Then, an exploratory preference value was calculated; i.e., the ratio of the amount of time spent exploring any one of the two familiar objects (familiarization session) or the novel object (retention session) over the total time spent exploring the two types of objects. An exploratory preference of $50 \%$ corresponds to chance, and a significantly higher exploratory preference reflects good recognition memory.

\section{Real-time RT-PCR}

For real-time RT-PCR, mice were sacrificed after the administration of LPS and/or betaine. Immediately after their decapitation, their hippocampi were rapidly dissected according to the method of Glowinski \& Iversen [23] and immersed in liquid nitrogen. Frozen hippocampi were stored at $-80^{\circ} \mathrm{C}$ until use. Total RNA was extracted using RNA-Bee Reagent (Tel-Test, Inc., Friendswood, TX, USA) according to the manufacturer's instructions, which is an improved version of the single-step method of RNA isolation [24]. Reverse transcription was performed with an ExScript RT reagent Kit (Perfect Real Time) or a PrimeScript RT reagent Kit (Perfect Real Time) (Takara Bio Inc., Otsu, Japan) under the conditions recommended by the manufacturer. Real-time PCR analysis was undertaken using SYBR Premix Ex Taq or SYBR Premix Ex Taq II (Takara Bio Inc.). Data collection involved using a Chromo4 real-time PCR detector and analysis with an 
Opticon Monitor 3 (Bio-Rad laboratories Inc., Hercules, CA, USA). The real-time PCR primers used in this study are listed in Table 1 . All primers were purchased from Takara Bio Inc. The real-time PCR conditions were as follows: initial denaturation at $95^{\circ} \mathrm{C}$ for $10 \mathrm{~s}$ followed by 40 cycles of $95^{\circ} \mathrm{C}$ for $5 \mathrm{~s}$ and $60^{\circ} \mathrm{C}$ for 20 s. The expression levels of the genes analyzed by real-time PCR were quantified by comparison with a standard curve and normalized relative to levels of $B$ actin.

\section{Data analysis}

Statistical analysis was performed, and the figures were produced using Prism 5 for Mac OS X (GraphPad Software, Inc., San Diego, CA, USA). It could not be assumed that the behavioral data were sampled from a Gaussian distribution; therefore, the data are expressed as median and interquartile range values. Significance was evaluated using the Mann-Whitney U-test for comparisons between two groups, and Kruskal-Wallis non-parametric one-way ANOVA followed by Bonferroni's test were used for multiple comparisons. The expression levels of each mRNA are shown as mean \pm S.E.M. An unpaired $t$ test (also with Welch-correction when F-test was significant) was used to compare two groups, and one-way ANOVA followed by Dunnett's test was used for multiple comparisons. The criterion for significance was $\mathrm{p}<0.05$.

Table 1 Gene-specific real time RT-PCR primer sequences.

\begin{tabular}{|c|c|c|}
\hline Gene & & Sequence $\left(5^{\prime}-3^{\prime}\right)$ \\
\hline \multirow[t]{2}{*}{ B-actin } & forward & TGACAGGATGCAGAAGGAGA \\
\hline & reverse & GCTGGAAGGTGGACAGTGAG \\
\hline \multirow[t]{2}{*}{ CD11b } & forward & TCACCCTCAAGGGCAACCTATC \\
\hline & reverse & AGGGCAAACGCAGAGTCATTAAAC \\
\hline \multirow[t]{2}{*}{ CD45 } & forward & TCCCAGCAGACAGGGTTGTTC \\
\hline & reverse & GTCCATTCTGGGCGGGATAG \\
\hline \multirow[t]{2}{*}{ cox-2 } & forward & GTGTGCGACATACTCAAGCAGGA \\
\hline & reverse & TGAAGTGGTAACCGCTCAGGTG \\
\hline \multirow[t]{2}{*}{ GAT2 } & forward & CCATCTTGGGCTTCATGTCTCA \\
\hline & reverse & CAGCTGGGACAAAGGCATCA \\
\hline \multirow[t]{2}{*}{ GFAP } & forward & ACCAGCTTACGGCCAACAGTG \\
\hline & reverse & TGTCTATACGCAGCCAGGTTGTTC \\
\hline \multirow[t]{2}{*}{ IL-1ß } & forward & TCCAGGATGAGGACATGAGCAC \\
\hline & reverse & GAACGTCACACACCAGCAGGTTA \\
\hline \multirow[t]{2}{*}{ IL-6 } & forward & CCACTTCACAAGTCGGAGGCTTA \\
\hline & reverse & GCAAGTGCATCATCGTTGTTCATAC \\
\hline \multirow[t]{2}{*}{ iNOS } & forward & GGAATGGAGACTGTCCCAGCA \\
\hline & reverse & GTCATGAGCAAAGGCGCAGA \\
\hline \multirow[t]{2}{*}{ Heme oxygenase-1 } & forward & TGCAGGTGATGCTGACAGAGG \\
\hline & reverse & TGTCTGGGATGAGCTAGTGCTGA \\
\hline \multirow[t]{2}{*}{ TNF- $\alpha$} & forward & AAGCCTGTAGCCCACGTCGTA \\
\hline & reverse & GGCACCACTAGTTGGTTGTCTITG \\
\hline
\end{tabular}

\section{Results}

Effects of repeated administration of betaine on LPSinduced memory impairment

In the Y-maze test, LPS treatment (30 $\mu \mathrm{g} /$ mouse, i.c.v.) significantly decreased the percentage of alternations 7 days after LPS injection (Mann-Whitney U-test, p < $0.05, \mathrm{U}=17.00$, Figure $2 \mathrm{~A}$ ) without changing the total number of arm entries (Mann-Whitney U-test, $\mathrm{p}=$ $0.199, \mathrm{U}=25.50$, Figure 2B). Repeated administration of betaine showed a bell-shaped dose-response relationship, and a dose of $0.163 \mathrm{mmol} / \mathrm{kg}$ (s.c.) significantly reversed the LPS-induced impairment of spontaneous alternations (Bonferroni's test, $\mathrm{p}<0.05$, Figure $2 \mathrm{~A}$ ) without changing the total number of arm entries (KruskalWallis non-parametric ANOVA, $\mathrm{H}(3)=2.021$, $\mathrm{p}=$ 0.568 , Figure 2B).

In the novel object recognition test, there was a decrease in preference for the novel object (Mann-Whitney U-test, $\mathrm{p}<0.01, \mathrm{U}=11.00$, Figure $2 \mathrm{D}$ ) without any changes in exploratory behavior during the familiarization session (Exploratory preference: Mann-Whitney Utest, $\mathrm{p}=0.222, \mathrm{U}=26.00$, Figure $2 \mathrm{C}$; Total exploratory time: Mann-Whitney U-test, $\mathrm{p}=0.610, \mathrm{U}=34.00$, Table 2) 12 days after injection of LPS (30 $\mu \mathrm{g} /$ mouse). Repeated administration of betaine also showed a bellshaped dose-response relationship, as was shown in the Y-maze test, and the same dose of betaine $(0.163 \mathrm{mmol} /$ $\mathrm{kg}$ ) significantly reversed the LPS-induced decrease in exploratory behavior (Bonferroni's test, $\mathrm{p}<0.05$, Figure 2D) without any changes in exploratory behavior during the familiarization session (Exploratory preference: Kruskal-Wallis non-parametric ANOVA, H(3) = 2.033, p = 0.566, Figure 2C; Total exploratory time: Kruskal-Wallis non-parametric ANOVA, $\mathrm{H}(3)=0.4513$, $\mathrm{p}=0.929$, Table 2).

\section{Effects of betaine on LPS-induced increases in mRNA expression of proinflammatory molecules}

Cytokines and proinflammatory molecules are important for the pathogenesis of LPS-induced memory impairment. We therefore investigated whether repeated administration of betaine could prevent LPS-induced increases in mRNA expression levels for proinflammatory molecules such as IL- $1 \beta$, TNF- $\alpha$, iNOS, and COX2. The mRNA expression levels of these inflammatory molecules transiently increased after LPS injection and recovered to baseline levels by $24 \mathrm{hr}$ after LPS injection (Figure 3$)$. LPS treatment (30 $\mu \mathrm{g} /$ mouse) significantly increased the mRNA expression levels of IL-1 $\beta$, TNF- $\alpha$, iNOS, COX-2, and IL-6 6 hr after LPS injection (unpaired t-test, $\mathrm{p}<0.05$ vs. corresponding sham control group, $\mathrm{t}=8.451,9.591,3.413,9.164$ and 8.749, respectively, $\mathrm{df}=5$, Figure 4$)$. Administration of betaine 


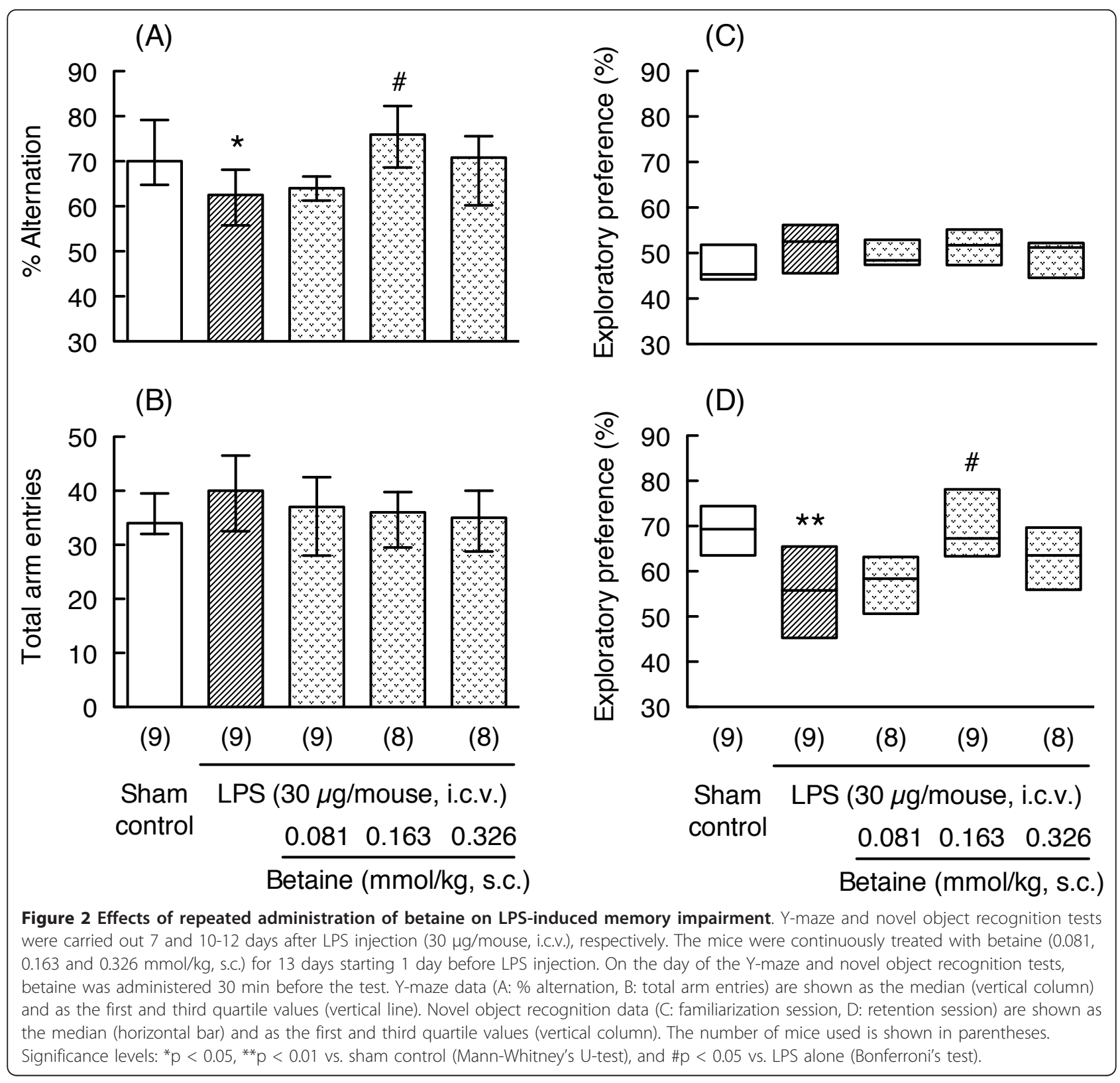

(0.081 and $0.163 \mathrm{mmol} / \mathrm{kg}$ ) did not prevent the LPSinduced increases in the levels of these mRNAs (oneway ANOVA; IL- $1 \beta$ : $F_{2,15}=2.535, p=0.113$; TNF- $\alpha$ : $\mathrm{F}_{2,15}=0.0308, \mathrm{p}=0.970$; iNOS: $\mathrm{F}_{2,15}=0.8014, \mathrm{p}=$
0.467; COX-2: $\mathrm{F}_{2,15}=0.0228, \mathrm{p}=0.978$; IL-6: $\mathrm{F}_{2,15}=$ $0.0009, \mathrm{p}=0.999$; Figure 4$)$. The mRNA expression level of heme oxygenase-1, a known marker of oxidative stress, was also significantly increased $6 \mathrm{hr}$ after LPS

Table 2 Total exploratory time in the familiar session.

\begin{tabular}{lll}
\hline Treatment & N & Total exploratory time (sec) (range) \\
\hline Sham control & 9 & $10.73(7.865-11.66)$ \\
LPS $(30 \mu \mathrm{g} /$ mouse, i.c.v. $)$ & 9 & $9.980(6.980-12.12)$ \\
LPS $(30 \mu \mathrm{g} /$ mouse, i.c.v. $)+$ betaine $(0.081 \mathrm{mmo} / \mathrm{kg}$, s.c. $)$ & 8 & $10.94(7.128-12.43)$ \\
LPS $(30 \mu \mathrm{g} /$ mouse, i.c.v. $)+$ betaine $(0.163 \mathrm{mmo} / \mathrm{kg}$, s.c. $)$ & 9 & $10.24(6.295-11.99)$ \\
LPS $(30 \mu \mathrm{g} /$ mouse, i.c.v. $)+$ betaine $(0.326 \mathrm{mmol} / \mathrm{kg}$, s.c. $)$ & 8 & $9.325(7.215-10.75)$ \\
\hline
\end{tabular}



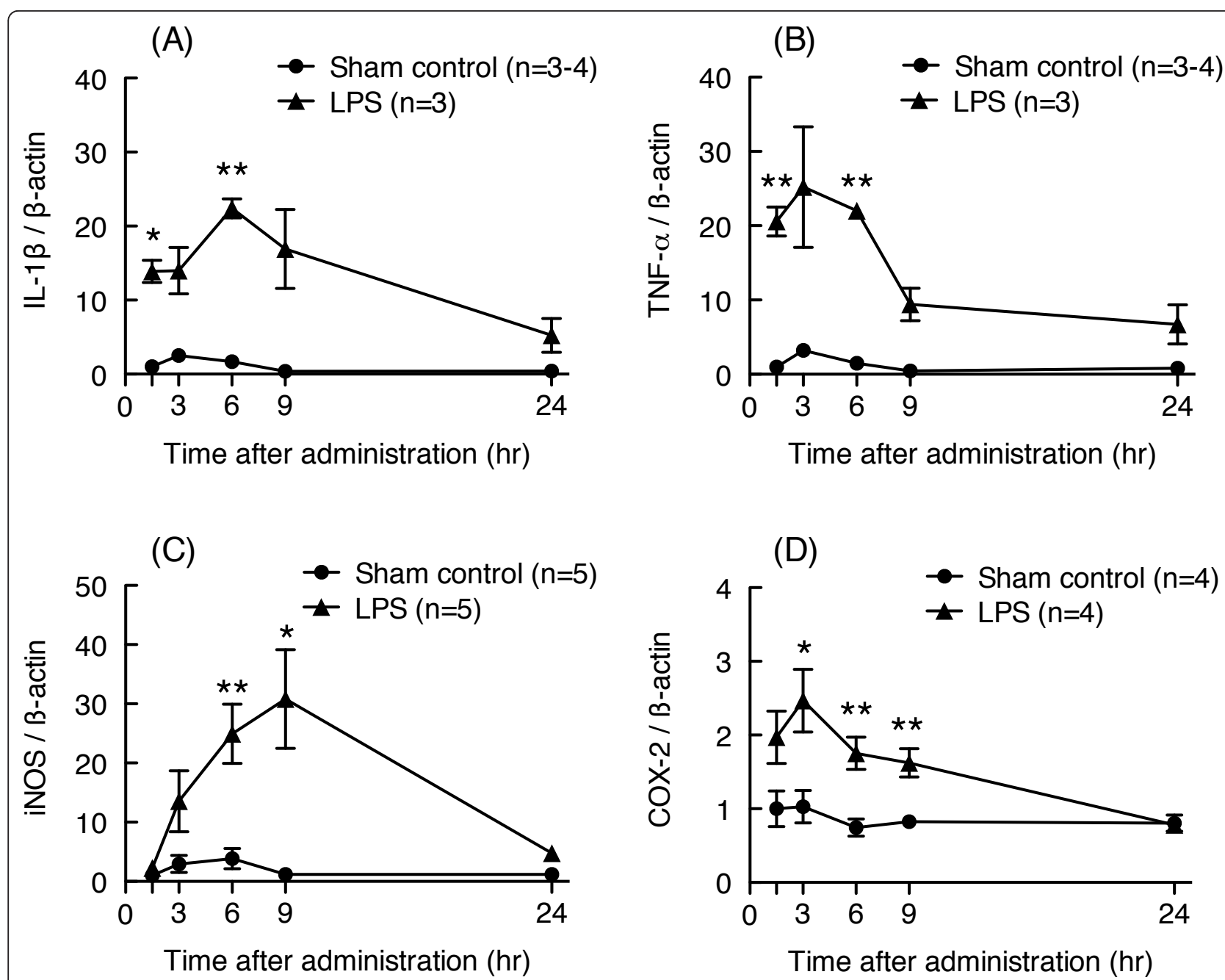

Figure 3 LPS-induced changes in levels of mRNA related to inflammation in the hippocampus. Time-dependent changes in mRNA expression levels for IL-1 $\beta$, TNF- $\alpha$, iNOS, and COX-2 in hippocampus after LPS injection are shown in figures (A), (B), (C), and (D), respectively. LPS $(30 \mu \mathrm{g} /$ mouse, i.c.v.) or saline was injected into the lateral ventricle of each mouse. The mice were sacrificed 1.5, 3, 6, 9, or 24 hr after LPS injection. Their mRNA levels were assessed by real-time RT-PCR. Each mRNA level was normalized to the mRNA level of $\beta$-actin as an endogenous control. Values are shown as the mean \pm S.E.M. for 3-5 mice, as shown in parentheses. Significance levels: ${ }^{*} p<0.05,{ }^{* *} p<0.01$ vs. corresponding sham control (unpaired t-test).

injection (unpaired t-test, $\mathrm{p}<0.05$; Sham control group: $1.000 \pm 0.084, \mathrm{n}=4$; LPS group: $3.688 \pm 0.520, \mathrm{n}=4$, Welch-corrected $\mathrm{t}=5.101, \mathrm{df}=3)$, and betaine treatment $(0.163 \mathrm{mmol} / \mathrm{kg})$ did not prevent this increase (unpaired t-test, $\mathrm{p}=0.961, \mathrm{t}=0.0508, \mathrm{df}=7$; LPS group: $3.688 \pm 0.520, \mathrm{n}=4$; LPS + betaine group: 3.730 $\pm 0.608, \mathrm{n}=5)$.

Effects of betaine on LPS-induced increases in mRNA expression levels of glial markers and the betaine transporter

Glial activation is also involved in the pathogenesis of LPS-induced memory impairment; therefore, to understand the effects of betaine on these cells, LPS-induced increases in mRNA expression levels for CD11b and
CD45, which are microglial markers, and glial fibrillary acidic protein (GFAP), a marker of astrocytes, were investigated. LPS treatment ( $30 \mu \mathrm{g} /$ mouse) significantly increased mRNA expression levels of CD11b, CD45, and GFAP $24 \mathrm{hr}$ after injection (unpaired t-test, $\mathrm{p}<0.01, \mathrm{t}=$ 4.425, $\mathrm{df}=14$ for CD11b; Welch-corrected $\mathrm{t}=5.083, \mathrm{df}$ $=7$ for CD45; Welch-corrected $\mathrm{t}=7.528, \mathrm{df}=8$ for GFAP, Figure 5); however, betaine treatment $(0.163$ $\mathrm{mmol} / \mathrm{kg}$ ) did not prevent LPS-induced increases in mRNA levels of these glial markers (unpaired t-test, $\mathrm{p}=$ $0.5603, \mathrm{df}=14$ for CD11b; $\mathrm{p}=0.9085, \mathrm{df}=14$ for $\mathrm{CD} 45 ; \mathrm{t}=0.3956, \mathrm{df}=14$ for GFAP, Figure 5).

Betaine may act on GAT2/BGT-1 expressed in neurons and/or glial cells to improve memory impairment; therefore, we examined the effects of LPS and betaine 
(A)

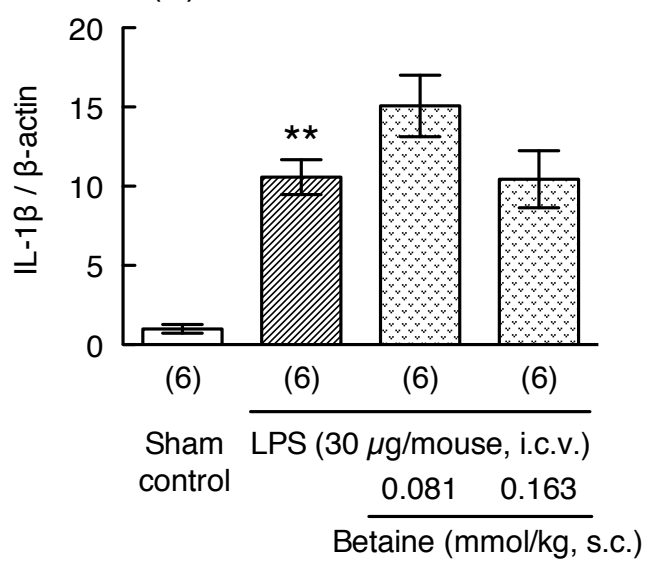

(C)

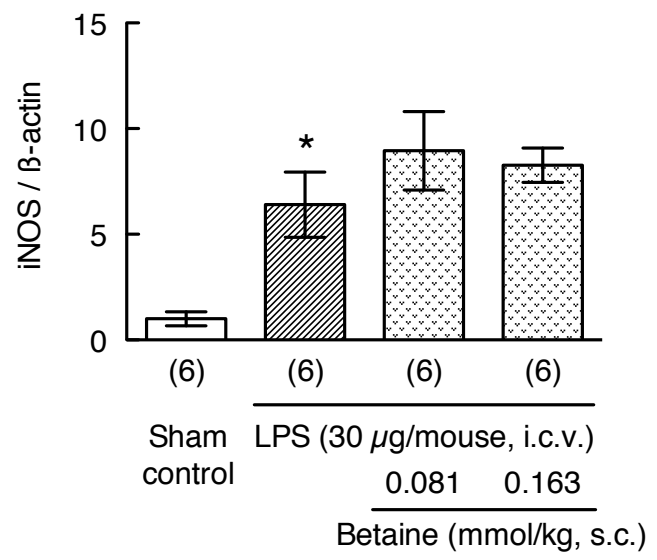

(B)

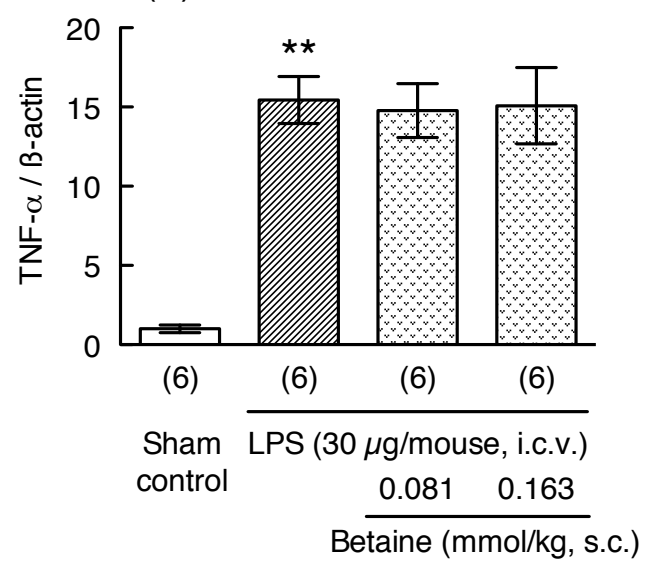

(D)

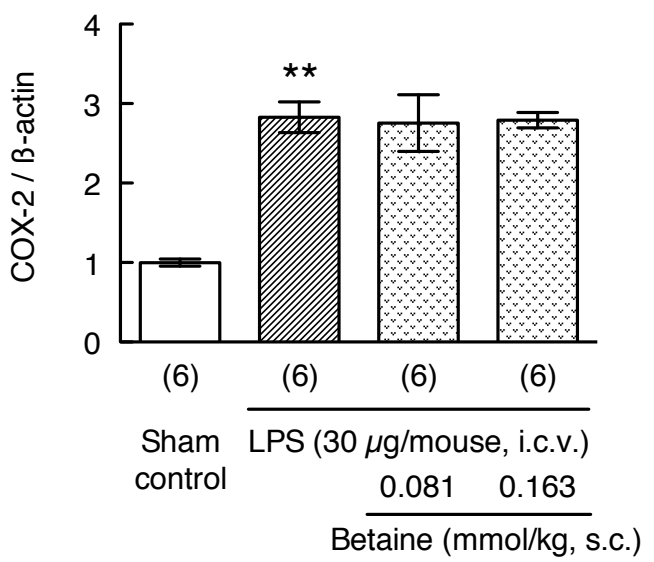

(E)

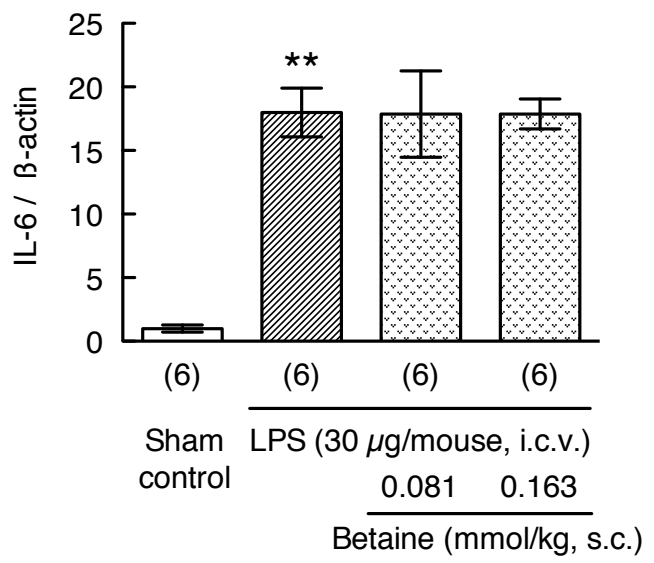

Figure 4 Effects of betaine on LPS-induced increases in the levels of mRNA related to inflammation. Mice were treated with betaine ( 0.081 and $0.163 \mathrm{mmol} / \mathrm{kg}$, s.c.) $24 \mathrm{hr}$ before and immediately before LPS injection (30 $\mathrm{\mu g} / \mathrm{mouse}$, i.c.v.), and sacrificed $6 \mathrm{hr}$ after LPS injection. mRNA levels in hippocampus were assessed by real-time RT-PCR. The level of each mRNA was normalized to the mRNA level of $\beta$-actin as an endogenous control. Values are shown as the mean \pm S.E.M. for 6 mice, as shown in parentheses. Significance levels: ${ }^{*} p<0.05,{ }^{* *} p<0.01$ vs. sham control (unpaired t-test). 
(B)

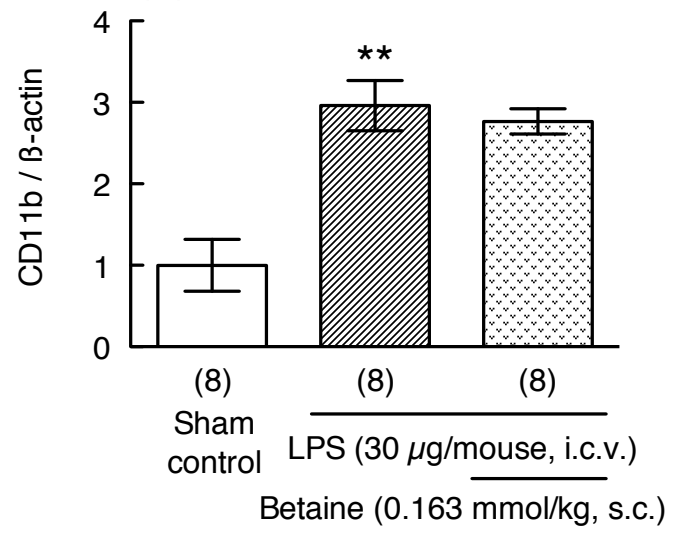

(D)

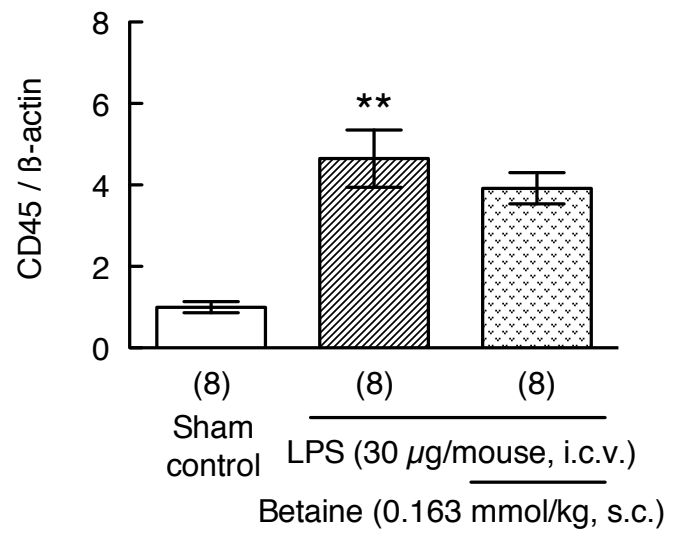

$(\mathrm{F})$

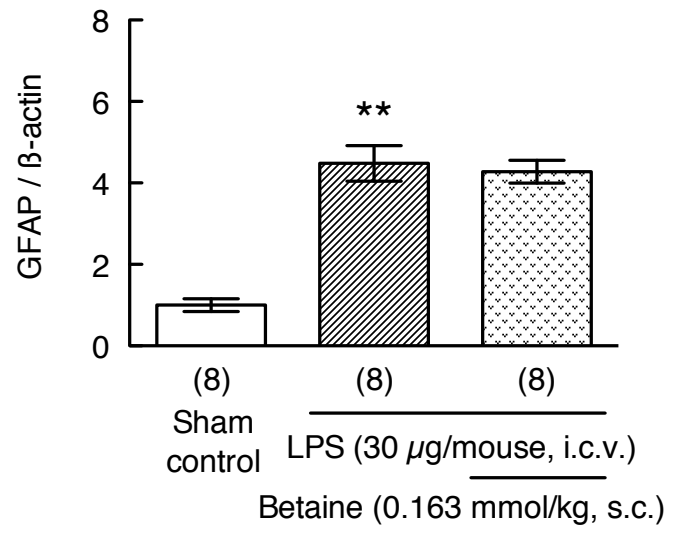

Figure 5 Effects of betaine on LPS-induced increases in mRNA expression levels for glial markers. Time-dependent changes in mRNA expression levels for CD11b, CD45, and GFAP in hippocampus 6, 9, 24, and $48 \mathrm{hr}$ after LPS injection (30 $\mathrm{mg} / \mathrm{mouse}$, i.c.v.) are shown in figures $(A),(C)$, and (E), respectively. The mice were treated with betaine $(0.163 \mathrm{mmol} / \mathrm{kg}, \mathrm{s.c}) .24 \mathrm{hr}$ before and immediately before LPS injection (30 $\mu \mathrm{g} /$ mouse, i.c.V.), and sacrificed $24 \mathrm{hr}$ after LPS injection. mRNA levels in hippocampus were assessed by real-time RT-PCR. The level of each mRNA was normalized to the mRNA level of $\beta$-actin as an endogenous control. Values are shown as the mean \pm S.E.M. for 4-8 mice, as shown in parentheses. Significance levels: ${ }^{*} p<0.05,{ }^{* *} p<0.01$ vs. corresponding sham control (unpaired t-test). 
on mRNA expression for GAT2. LPS treatment $(30 \mu \mathrm{g} /$ mouse) significantly increased mRNA expression for GAT2 $24 \mathrm{hr}$ after injection (unpaired t-test, $\mathrm{p}<0.05$, Welch-corrected $t=3.489$, $d f=6$, Figure 6A, B). Interestingly, betaine $(0.163 \mathrm{mmol} / \mathrm{kg})$ prevented this LPSinduced increase in GAT2 mRNA levels (unpaired ttest, $\mathrm{p}<0.05, \mathrm{t}=2.301, \mathrm{df}=12$, Figure $6 \mathrm{~B}$ ). These results may indicate that repeated administration of

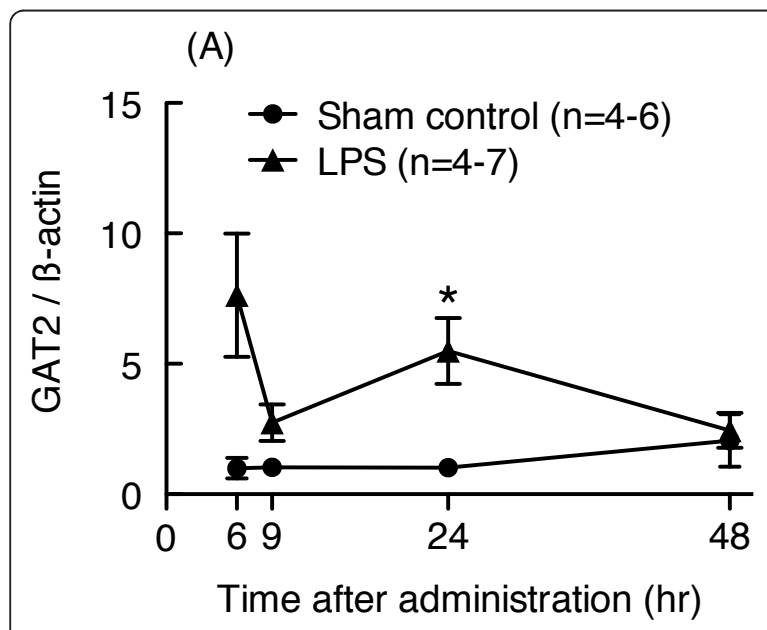

(B)

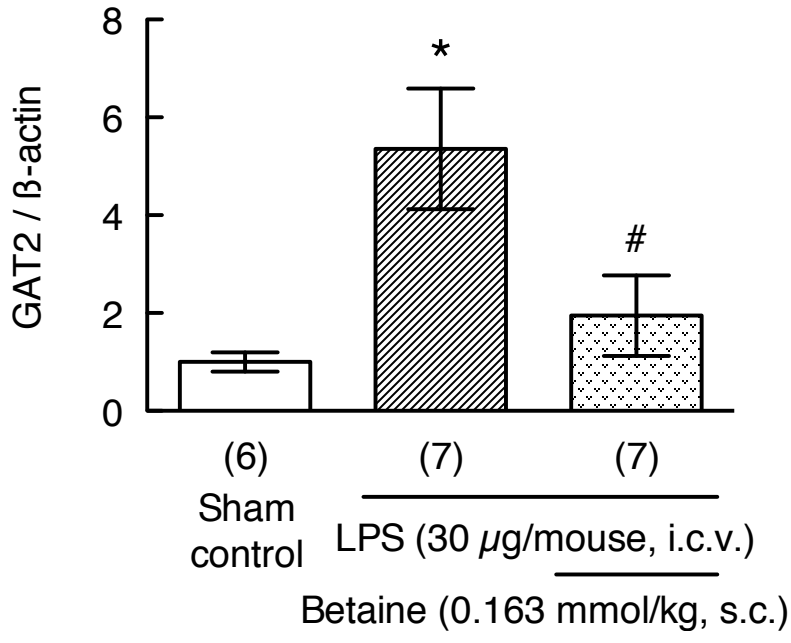

Figure 6 Effects of betaine on LPS-induced increases in mRNA expression levels for GAT2. Time-dependent changes in GAT2 mRNA expression in hippocampus 6, 9, 24, and $48 \mathrm{hr}$ after LPS injection (30 $\mu \mathrm{g} /$ mouse, i.c.v.) are shown in the upper panel (A). Mice were treated with betaine $(0.163 \mathrm{mmol} / \mathrm{kg}$, s.c.) $24 \mathrm{hr}$ before and immediately before LPS injection ( $30 \mu \mathrm{g} /$ mouse, i.c.v.), and sacrificed $24 \mathrm{hr}$ after LPS injection. mRNA levels in hippocampus were assessed by real-time RT-PCR. The level of each mRNA was normalized to the mRNA level of $\beta$-actin as an endogenous control. Values are shown as the mean \pm S.E.M. for 4-7 mice, as shown in parentheses. Significance levels: ${ }^{*} p<0.05$ vs. sham control, \#p $<$ 0.05 vs. LPS alone (unpaired t-test). betaine is not necessary to prevent LPS-induced memory impairment. Therefore, as our next experiment, we conducted behavioral experiments after subacute ( $1 \mathrm{hr}$ before, 1 and $24 \mathrm{hr}$ after LPS injection) or acute ( $1 \mathrm{hr}$ before or after LPS injection) administration of betaine.

\section{Effects of subacute administration of betaine on LPS- induced memory impairment}

LPS treatment (30 $\mathrm{g}$ /mouse) significantly decreased the percentage of alternations in the Y-maze test (MannWhitney U-test, $\mathrm{p}<0.01, \mathrm{U}=59.0$, Figure 7A) and the degree of preference for the novel object (Mann-Whitney U-test, $\mathrm{p}<0.01, \mathrm{U}=58.0$, Figure $7 \mathrm{D})$. Subacute administration of betaine $(0.163 \mathrm{mmol} / \mathrm{kg})$ significantly reversed LPS-induced memory impairment in the Ymaze (Mann-Whitney U-test, $\mathrm{p}<0.01, \mathrm{U}=64.0$, Figure 7A) and novel object recognition tests (Mann-Whitney U-test, $\mathrm{p}<0.05, \mathrm{U}=70.0$, Figure 7D). These treatments had no influences on the total number of arm entries in the Y-maze test (Figure 7B) or on exploratory behavior during the familiarization session in the novel object recognition test (Figure $7 \mathrm{C}$, Table 3 ).

\section{Effects of acute administration of betaine on LPS-induced memory impairment}

We further examined whether a single administration of betaine is able to prevent LPS-induced memory impairment (experimental schedule shown in Figure 1C). Interestingly, a single administration of betaine $(0.163$ $\mathrm{mmol} / \mathrm{kg}$ ) $1 \mathrm{hr}$ after LPS injection also significantly reversed LPS-induced impairment of spontaneous alternation (Mann-Whitney U-test, $\mathrm{p}<0.05, \mathrm{U}=29.5$, Figure 8A); however, a single administration of betaine 1 hr before LPS injection did not reverse LPS-induced impairment of spontaneous alternation (Mann-Whitney U-test, $\mathrm{p}=0.795, \mathrm{U}=67.0$, Figure 8A).

\section{Discussion}

It has been reported that betaine suppresses expression of proinflammatory molecules such as COX-2, iNOS, and TNF- $\alpha$; and increases oxidative stress in aged rat kidney [6,7]. Betaine also prevents chronic ethanol consumption-induced oxidative stress in brain synaptosomes [25]. These reports suggest that betaine might be a useful compound for preventing neurodegenerative disorders and/or other diseases involving inflammatory processes and oxidative stress; however, the effects of betaine on memory impairment involving neuroinflammatory and/or oxidative stress are not well known. Therefore, the effects of betaine on LPS-induced memory impairment were evaluated. Repeated administration of betaine $(0.163 \mathrm{mmol} / \mathrm{kg})$ improved LPS-induced memory impairment in the Y-maze and novel object recognition tests, with a bell-shaped dose-response 


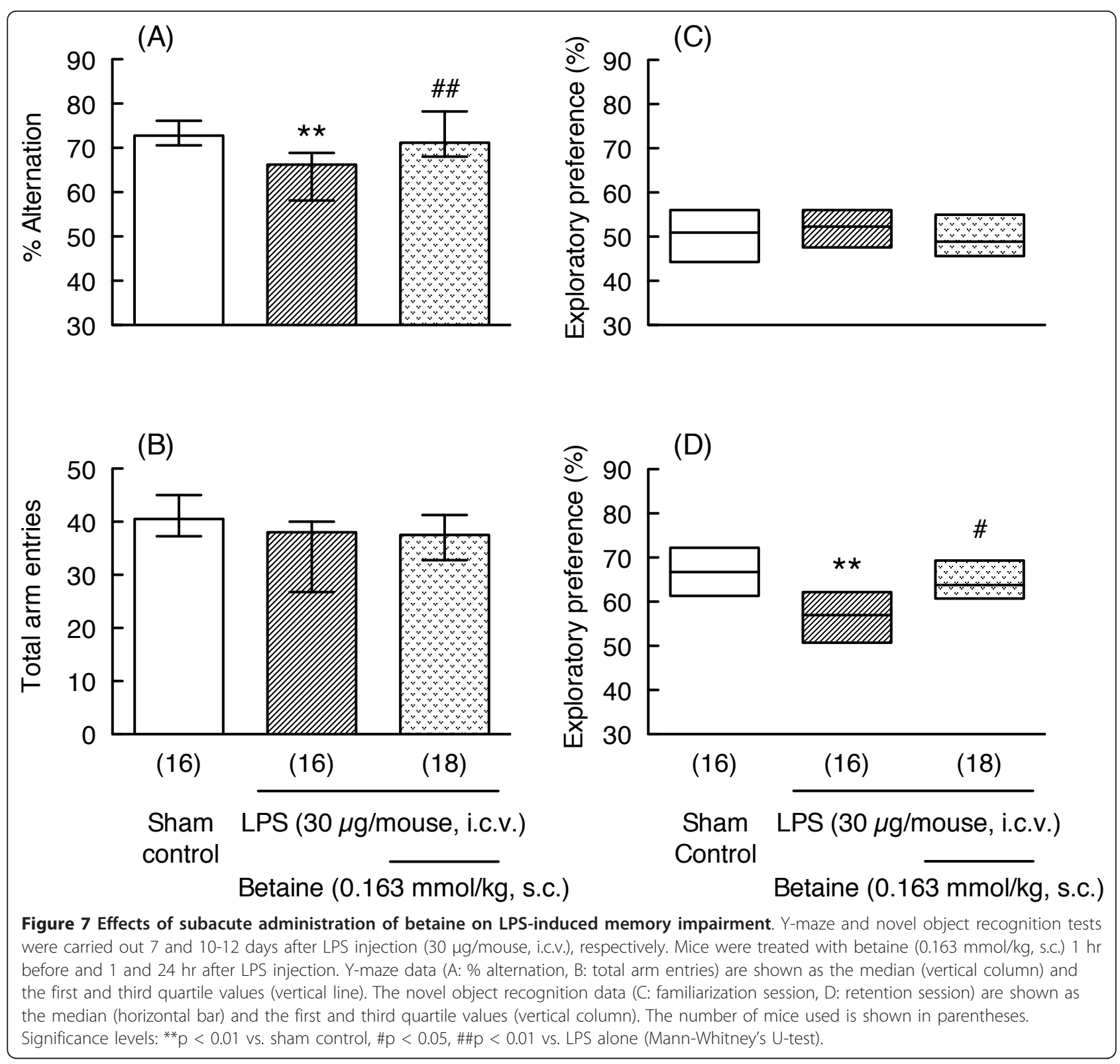

relationship. Our findings suggest that betaine improves LPS-induced memory impairment, but it is possible that the preference for the object changed due to some perceptual effects rather than memory effects, and/or induction of sickness behavior may have changed the innate preference for an object without affecting memory processes. However, we used identical objects in the familiarization sessions, after which one of these objects was randomly replaced with a novel object. Further, sickness behavior is usually assessed within $24 \mathrm{hr}$ of induction, but in our protocol the behavioral experiments were conducted 7 to 12 days after LPS injection. On these days, no sickness-like behavior was seen, as in other investigations; therefore, we think that the effects

Table 3 Total exploratory time in the familiar session.

\begin{tabular}{lll}
\hline Treatment & $\mathbf{N}$ & Total exploratory time (sec) (range) \\
\hline Sham control & 16 & $8.600(5.918-10.40)$ \\
LPS $(30 \mu \mathrm{g} /$ mouse, i.c.v. $)$ & 16 & $7.810(6.813-9.165)$ \\
LPS $(30 \mu \mathrm{g} /$ mouse, i.c.v. $)+$ betaine $(0.163 \mathrm{mmol} / \mathrm{kg}$, s.c. $)$ & 18 & $8.055(5.540-10.87)$ \\
\hline
\end{tabular}

See Fig. 7 for details. 


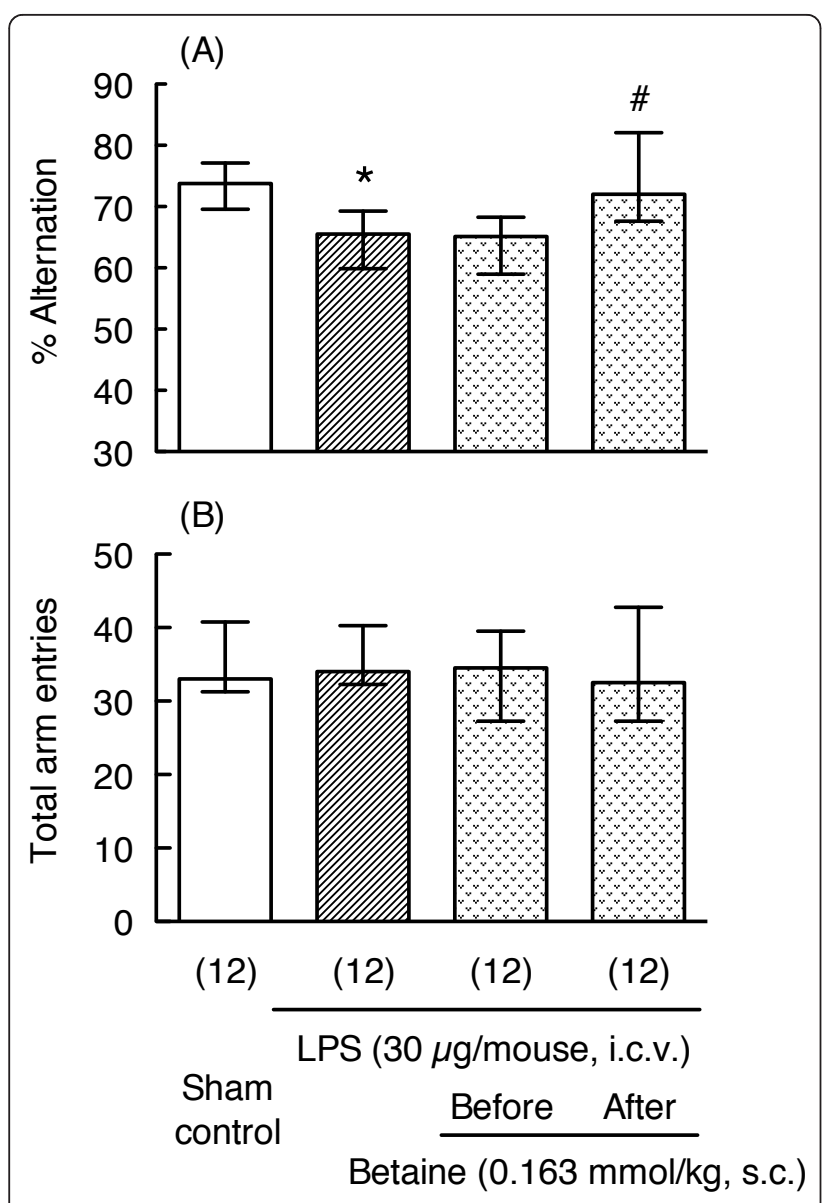

Figure 8 Effects of acute administration of betaine on LPSinduced memory impairment in the Y-maze test. The Y-maze test was carried out 7 days after LPS ( $30 \mu \mathrm{g} /$ mouse, i.c.v.) injection. The mice were treated with betaine $(0.163 \mathrm{mmol} / \mathrm{kg}$, s.c.) $1 \mathrm{hr}$ before or $1 \mathrm{hr}$ after LPS injection. Y-maze data (A: \% alternation, B: total arm entries) are shown as the median (vertical column) and the first and third quartile values (vertical line). The number of mice used is shown in parentheses. Significance levels: ${ }^{*} p<0.05$ vs. sham control (Mann-Whitney's U-test), \#p $<0.05$ vs. LPS alone (MannWhitney's U-test).

of LPS and/or betaine reflect memory function rather than other effects. Taken together, these results suggest that betaine has a preventative effect on LPS-induced memory impairment caused by neuroinflammatory responses.

As described in Background, LPS induces expression of proinflammatory molecules and glial activation within several days of LPS injection. For example, Szczepanik \& Ringheim [26] reported that i.c.v. injection of LPS induces production of proinflammatory cytokines such as IL- $1 \alpha, \mathrm{IL}-1 \beta, \mathrm{IL}-6$, and TNF- $\alpha$ in mouse hippocampus and cortex. These increases in the expression levels of proinflammatory cytokines peaked about $6-9 \mathrm{hr}$ after LPS injection. LPS-induced neuronal injury requires the presence of microglia and Toll-like receptor 4-dependent pathways [27]. Choi et al. [28] reported that i.c.v. injection of LPS induces neuronal damage and activation of microglia and astrocytes in hippocampus $24 \mathrm{hr}$ after LPS injection. Therefore, we investigated whether betaine could suppress LPS-induced increases in mRNA expression levels of various proinflammatory molecules and glial markers in hippocampus concurrently with the observed improvements in memory impairment. LPS induced a transient increase in mRNA expression levels for IL- $1 \beta$, TNF- $\alpha$, iNOS, and COX-2; and these increases returned to sham-control levels by $24 \mathrm{hr}$ after LPS injection; however, betaine ( 0.081 or $0.163 \mathrm{mmol} / \mathrm{kg}$ ) did not affect the LPS-induced increases in mRNA levels for these inflammatory molecules.

LPS treatment (30 $\mu \mathrm{g} /$ mouse) also increased mRNA expression levels of the microglial markers CD11b and CD 45, and the astrocytic marker GFAP; however, betaine also did not prevent the LPS-induced increases in mRNA levels for these glial markers. Our results indicate that betaine does not suppress mRNA expression of proinflammatory molecules or glial markers, and the mechanism behind the ameliorating effects of betaine on memory impairment is not mediated by the expression of these genes, which is the mechanism by which betaine suppresses the expression of proinflammatory molecules and increased oxidative stress in aged rat kidney $[6,7]$. This finding indicates that the mechanism behind the actions of betaine in the central nervous system is different from that in kidney.

Four different subtypes of GAT have been cloned and are termed GAT1, GAT2, GAT3, and GAT4 in mice (GAT-1, BGT-1, GAT-2 and GAT-3, respectively, in rats and humans) [29]. GAT2/BGT-1 transports both GABA and betaine $[9,30]$. In renal epithelial cells, GAT2/BGT-1 is a basolateral membrane protein that protects cells in the hypertonic inner medulla by mediating betaine uptake and accumulation [5]. In the central nervous system, it has been reported that betaine content and BGT-1 mRNA levels are increased in brain of rats with hyperosmotic serum induced by the injection and drinking of $\mathrm{NaCl}$ solution [31,32]. In addition, protein and mRNA expressions of GAT2/BGT-1 are upregulated in mouse and rat astrocyte primary cultures exposed to hyperosmotic conditions [10,33]. These results suggest that betaine and GAT2/BGT-1 play important roles in osmotic regulation in the central nervous system. Moreover, expression of BGT-1 is increased in astrocytes after kainate-induced neuronal injury in rat hippocampus [11]. While betaine and GAT2/BGT-1 may be involved in neuronal dysfunction caused by neurodegeneration or neuronal injury, their physiological roles are not yet known. In the present study, we examined mRNA expression for GAT2 after treatment with LPS and/or betaine in mouse 
hippocampus. LPS treatment (30 $\mu \mathrm{g} /$ mouse) significantly increased mRNA expression for GAT2 $24 \mathrm{hr}$ after LPS injection. Interestingly, betaine $(0.163 \mathrm{mmol} / \mathrm{kg})$ blocked this LPS-induced increase in mRNA expression for GAT2, suggesting that betaine and its transporter, GAT2/BGT-1, play important roles in neuronal dysfunction caused by neuronal injury.

It is known that the changes that occur during the early phase after LPS treatment are crucial to delayed neuronal impairment such as the memory impairment shown in this study. To elucidate the mechanisms underlying the effects of betaine, we considered that administration of betaine during the early phase after LPS injection might be necessary for preventing LPSinduced memory because mRNA expression levels for GAT2 transiently increased after LPS injection and recovered by $48 \mathrm{hr}$ after LPS injection. Interestingly, either subacute ( $1 \mathrm{hr}$ before, 1 and $24 \mathrm{hr}$ after the LPS injection) or single (1 hr after the LPS injection) administration of betaine prevented LPS-induced memory impairment, but this effect was not seen when betaine was given $1 \mathrm{hr}$ before LPS injection. Consistent with betaine's effect in alleviating LPS-induced delayed memory impairment, betaine also significantly reduced LPSinduced increases in GAT2 mRNA levels in hippocampus. These data suggest that during the early period after LPS injection, betaine plays a crucial role in preventing LPS-induced neuronal dysfunction. On the other hand, a single administration of betaine, $1 \mathrm{hr}$ before LPS injection, did not prevent LPS-induced memory impairment. This finding that betaine has a neuroprotective effect on delayed memory impairment even when administered after LPS injection has important therapeutic implications. Excitotoxicity has been implicated in the etiology of ischemic stroke and chronic neurodegenerative disorders. Hence, the development of novel neuroprotective molecules that ameliorate excitotoxic brain damage is being vigorously pursued. Indeed, betaine attenuates glutamate-induced neurotoxicity in primary cultured brain cells [34]. Montoliu et al. [35] reported that a family of trialkylglycines significantly prevent excitotoxic neuronal death in models of neurodegeneration. Since dietary and supplementary administration of betaine has been studied in humans, if the detailed mechanism of betaine could be clarified, it could become a candidate for treatment of cognitive dysfunction in disorders such as Alzheimer's disease and senile dementia.

\section{Conclusions}

Betaine improves LPS-induced memory impairment and blocks LPS-induced increases in mRNA expression for GAT2; however, betaine does not prevent LPS-induced increases in mRNA expression of proinflammatory molecules or glial markers. These results suggest that betaine has protective effects against LPS-induced memory impairment that are mediated through unique mechanisms involving betaine actions on GAT2, which is involved in the development of memory impairment, without affecting proinflammatory molecules or glial markers.

\section{Acknowledgements}

This study was supported in part by a collaboration with the Local Communities Project from MEXT (Ministry of Education, Culture, Sports, Science, and Technology) and the Academic Frontier Project for Private Universities, which matched the subsidy provided by MEXT.

\section{Author details}

${ }^{1}$ Laboratory of Neuropsychopharmacology, Graduate School of Environmental and Human Sciences, Meijo University, 150 Yagotoyama, Tenpaku-ku, Nagoya 468-8503, Japan. ${ }^{2}$ Department of Chemical Pharmacology, Faculty of Pharmaceutical Sciences, Meijo University, 150 Yagotoyama, Tenpaku-ku, Nagoya 468-8503, Japan.

\section{Authors' contributions}

MT carried out the behavioral experiments. YN and AE carried out the realtime RT-PCR. MM participated in the design of the study, performed the statistical analysis, drafted the manuscript, and helped to carry out the behavioral experiments and real-time RT-PCR. MH conceived the study, participated in its design and coordination, and helped to draft the manuscript. All of the authors have read and approved the final manuscript.

\section{Competing interests}

The authors declare that they have no competing interests.

Received: 23 February 2011 Accepted: 4 November 2011

Published: 4 November 2011

\section{References}

1. Craig SA: Betaine in human nutrition. Am J Clin Nutr 2004, 80:539-549.

2. Zeisel SH, Mar MH, Howe JC, Holden JM: Concentrations of cholinecontaining compounds and betaine in common foods. J Nutr 2003, 133:1302-1307.

3. Chen TH, Murata N: Glycinebetaine: an effective protectant against abiotic stress in plants. Trends Plant Sci 2008, 13:499-505.

4. Zeisel SH, Blusztajn JK: Choline and human nutrition. Annu Rev Nutr 1994, 14:269-296.

5. Kempson SA, Montrose MH: Osmotic regulation of renal betaine transport: transcription and beyond. Pflugers Arch 2004, 449:227-234

6. Go EK, Jung KJ, Kim JM, Lim H, Lim HK, Yu BP, Chung HY: Betaine modulates age-related NF-KB by thiol-enhancing action. Biol Pharm Bull 2007, 30:2244-2249.

7. Go EK, Jung K, Kim JY, Yu BP, Chung HY: Betaine suppresses proinflammatory signaling during aging: the involvement of nuclear factor-KB via nuclear factor-inducing kinase//kB kinase and mitogenactivated protein kinases. J Gerontol A Biol Sci Med Sci 2005, 60:1252-1264.

8. Borden LA, Smith KE, Gustafson EL, Branchek TA, Weinshank RL: Cloning and expression of a betaine/GABA transporter from human brain. $J$ Neurochem 1995, 64:977-984.

9. Yamauchi A, Uchida S, Kwon HM, Preston AS, Robey RB, Garcia-Perez A, Burg MB, Handler JS: Cloning of a $\mathrm{Na}^{+}$- and $\mathrm{Cl}^{-}$-dependent betaine transporter that is regulated by hypertonicity. J Biol Chem 1992, 267:649-652

10. Olsen M, Sarup A, Larsson OM, Schousboe A: Effect of hyperosmotic conditions on the expression of the betaine-GABA-transporter (BGT-1) in cultured mouse astrocytes. Neurochem Res 2005, 30:855-865.

11. Zhu XM, Ong WY: Changes in GABA transporters in the rat hippocampus after kainate-induced neuronal injury: decrease in GAT-1 and GAT-3 but upregulation of betaine/GABA transporter BGT-1. J Neurosci Res 2004, 77:402-409. 
12. Takanaga H, Ohtsuki S, Hosoya K, Terasaki T: GAT2/BGT-1 as a system responsible for the transport of $\gamma$-aminobutyric acid at the mouse blood-brain barrier. J Cereb Blood Flow Metab 2001, 21:1232-1239.

13. Iwai $T$, linuma $Y$, Kodani $R, O k a ~ J:$ Neuromedin $U$ inhibits inflammationmediated memory impairment and neuronal cell-death in rodents. Neurosci Res 2008, 61:113-119.

14. Tanaka S, Ide M, Shibutani T, Ohtaki H, Numazawa S, Shioda S, Yoshida T: Lipopolysaccharide-induced microglial activation induces learning and memory deficits without neuronal cell death in rats. J Neurosci Res 2006, 83:557-566.

15. Yamada K, Komori Y, Tanaka T, Senzaki K, Nikai T, Sugihara H, Kameyama T, Nabeshima T: Brain dysfunction associated with an induction of nitric oxide synthase following an intracerebral injection of lipopolysaccharide in rats. Neuroscience 1999, 88:281-294.

16. Block ML, Hong JS: Microglia and inflammation-mediated neurodegeneration: multiple triggers with a common mechanism. Prog Neurobiol 2005, 76:77-98.

17. Eikelenboom $\mathrm{P}$, Veerhuis $\mathrm{R}$, Scheper W, Rozemuller AJ, van Gool WA, Hoozemans JJ: The significance of neuroinflammation in understanding Alzheimer's disease. J Neural Transm 2006, 113:1685-1695.

18. Minghetti L: Role of inflammation in neurodegenerative diseases. Curr Opin Neurol 2005, 18:315-321.

19. Haley TJ, McCormick WG: Pharmacological effects produced by intracerebral injection of drugs in the conscious mouse. $\mathrm{Br} J$ Pharmacol Chemother 1957, 12:12-15.

20. Hiramatsu M, Sasaki M, Nabeshima T, Kameyama T: Effects of dynorphin A (1-13) on carbon monoxide-induced delayed amnesia in mice. Pharmacol Biochem Behav 1997, 56:73-79.

21. Sarter M, Bodewitz G, Stephens DN: Attenuation of scopolamine-induced impairment of spontaneous alteration behaviour by antagonist but not inverse agonist and agonist $\beta$-carbolines. Psychopharmacology (Berl) 1988, 94:491-495.

22. Nagai T, Takuma K, Kamei H, Ito $Y$, Nakamichi N, Ibi D, Nakanishi $Y$, Murai M, Mizoguchi H, Nabeshima T, Yamada K: Dopamine D1 receptors regulate protein synthesis-dependent long-term recognition memory via extracellular signal-regulated kinase $1 / 2$ in the prefrontal cortex. Learn Mem 2007, 14:117-125.

23. Glowinski J, Iversen LL: Regional studies of catecholamines in the rat brain. I. The disposition of $\left[{ }^{3} \mathrm{H}\right]$ norepinephrine, $\left[{ }^{3} \mathrm{H}\right]$ dopamine and $\left[{ }^{3} \mathrm{H}\right]$ dopa in various regions of the brain. J Neurochem 1966, 13:655-669.

24. Chomczynski P, Sacchi N: Single-step method of RNA isolation by acid guanidinium thiocyanate-phenol-chloroform extraction. Anal Biochem 1987, 162:156-159.

25. Kanbak G, Arslan OC, Dokumacioglu A, Kartkaya K, Inal ME: Effects of chronic ethanol consumption on brain synaptosomes and protective role of betaine. Neurochem Res 2008, 33:539-544.

26. Szczepanik AM, Ringheim GE: IL-10 and glucocorticoids inhibit Aß(1-42)and lipopolysaccharide-induced pro-inflammatory cytokine and chemokine induction in the central nervous system. J Alzheimers Dis 2003, 5:105-117.

27. Lehnardt S, Massillon L, Follett P, Jensen FE, Ratan R, Rosenberg PA, Volpe JJ, Vartanian T: Activation of innate immunity in the CNS triggers neurodegeneration through a Toll-like receptor 4-dependent pathway. Proc Natl Acad Sci USA 2003, 100:8514-8519.

28. Choi SH, Langenbach R, Bosetti F: Genetic deletion or pharmacological inhibition of cyclooxygenase-1 attenuate lipopolysaccharide-induced inflammatory response and brain injury. FASEB J 2008, 22:1491-1501.

29. Madsen KK, Clausen RP, Larsson OM, Krogsgaard-Larsen P, Schousboe A, White HS: Synaptic and extrasynaptic GABA transporters as targets for anti-epileptic drugs. J Neurochem 2009, 109(Suppl 1):139-144.

30. Borden LA: GABA transporter heterogeneity: pharmacology and cellular localization. Neurochem Int 1996, 29:335-356.

31. Bitoun M, Tappaz M: Gene expression of taurine transporter and taurine biosynthetic enzymes in brain of rats with acute or chronic hyperosmotic plasma. A comparative study with gene expression of myo-inositol transporter, betaine transporter and sorbitol biosynthetic enzyme. Brain Res Mol Brain Res 2000, 77:10-18.

32. Lien $\mathrm{YH}$, Shapiro Jl, Chan L: Effects of hypernatremia on organic brain osmoles. J Clin Invest 1990, 85:1427-1435.
33. Bitoun M, Tappaz M: Gene expression of the transporters and biosynthetic enzymes of the osmolytes in astrocyte primary cultures exposed to hyperosmotic conditions. Glia 2000, 32:165-176.

34. Park MJ, Kim SR, Huh H, Jung JH, Kim YC: Betaine attenuates glutamateinduced neurotoxicity in primary cultured brain cells. Archives of Pharmacal Research 1994, 17:343-347.

35. Montoliu C, Humet M, Canales JJ, Burda J, Planells-Cases R, SanchezBaeza F, Carbonell T, Perez-Paya E, Messeguer A, Ferrer-Montiel A, Felipo V: Prevention of in vivo excitotoxicity by a family of trialkylglycines, a novel class of neuroprotectants. J Pharmacol Exp Ther 2002, 301:29-36.

doi:10.1186/1742-2094-8-153

Cite this article as: Miwa et al:: Effects of betaine on lipopolysaccharideinduced memory impairment in mice and the involvement of GABA transporter 2. Journal of Neuroinflammation 2011 8:153.

\section{Submit your next manuscript to BioMed Central and take full advantage of:}

- Convenient online submission

- Thorough peer review

- No space constraints or color figure charges

- Immediate publication on acceptance

- Inclusion in PubMed, CAS, Scopus and Google Scholar

- Research which is freely available for redistribution

Submit your manuscript at www.biomedcentral.com/submit
Ciomed Central 